\title{
Prevalence and comparison of dental caries in 12 year old school going children in rural and urban areas of Ferozepur city using sic index
}

\author{
Bhawna Arora $^{1 *}$, Vineet I. S. Khinda ${ }^{2}$, Shiminder Kallar ${ }^{2}$, Nitika Bajaj ${ }^{2}$ and Gurlal Singh Brar ${ }^{2}$ \\ ${ }^{1}$ Department of Pedodontics and Preventive Dentistry, Adesh institute of dental sciences and research, Bathinda, India \\ ${ }^{2}$ Department of Pedodontics and Preventive Dentistry, Genesis institute of dental sciences and research, Ferozepur, India
}

\begin{abstract}
Introduction: Dental caries afflicts humans of all ages and in all regions of the world. The distribution and severity of oral diseases vary in different parts of the world and within the same region. The epidemiological studies help in assessment of need for planning of oral health services or organization of public health intervention programmes.

Materials and method: The present study was undertaken to estimate and compare the prevalence of dental caries in 12 years old school going children in rural and urban sets of population in Ferozepur City using $\mathrm{SiC}$ index. A school based survey was administered to 1000 school going children residing in urban and rural areas of Ferozepur city, Punjab. 500 subjects each from age group of 12 years +11 months were randomly selected using stratified sampling method from respective areas. Data was collected through a questionnaire and clinical examination was done by a single examiner using BOHS (Basic Oral Health Survey) method. DMFT (Decayed, Missing and Filled teeth) was measured according to WHO (World Health Organization) criteria and SiC(Significant index of caries) values were calculated and compared including risk factors like socioeconomic status, oral hygiene measures, parent's education, frequent snacking and dietary habits.

Results: The overall prevalence of dental caries was found to be $47.8 \%$.Rural study population had higher caries prevalence of $53.8 \%$ as compared to the urban with a prevalence of $39.8 \%$. The caries prevalence was higher in females (50.8\%) as compared to males (44.8\%). The mean DMFT of the total study population was 1.17 with the mean DMFT values amongst rural and urban population of 1.43 and 0.92 respectively. The mean $\mathrm{SiC}$ value of the study population was 2.99 with a value of 2.55 in urban and 3.42 in rural study population.

Discussion: The prevalence of dental caries score showed significant association with all independent variables like brushing frequency, visit to dentist, dietary habits, gender, sweetened milk, parent's education and frequency of snacking in descending order. The lack of dental health awareness, poor oral hygiene measures, socioeconomic status, gender variations, improper dietary habits and less utilization of dental health care services in Ferozepur are the risk factors associated with the high prevalence of dental caries.
\end{abstract}

\section{Introduction}

Dental caries is the outcome of a multiple complex process involving factors like diet, microorganisms, trace elements, saliva, genetic predisposition and tooth morphology. Apart from these, many related factors like individual, social, environmental and cultural factors are also responsible [1-5].

According to National Oral Health Survey, 2002-2003, caries prevalence in India was $51.9 \%$ (mean deft $=2$ ), $53.8 \%$ (mean DMFT $=1.8$ ) and $63.1 \%$ (mean DMFT=2.4) at ages 5, 12 and 15 years [6,7]. The prevalence rates and experience of dental caries are tending to increase in developing countries with a decline in caries in most industrialized countries. The 'Prevalence' of dental caries in an individual is obtained by calculating DMFT, which is the most common index used. The WHO goal indicates that a maximum of 3 teeth as a mean may be affected by caries at the age of 12 . However, a low mean caries level such as ' 3.0 ' does not exclude a number of individuals with considerably higher DMFT values in the same population (Global goals for oral health in year 2000 FDI).

Expressing caries prevalence as the mean DMFT value does not correctly reflect the skewed distribution, leaving high caries groups undiscovered in the population. Based on these features, a new index called the 'Significant caries index' $(\mathrm{SiC})$ was proposed by the WHO to draw attention to individuals with the highest caries scores in each population [8]. The $\mathrm{SiC}$ is the mean $\mathrm{dmft} / \mathrm{DMFT}$ of one third of the study group with the highest caries score. As a following step, it has been proposed that the SiC Index for countries should be less than DMFT 3 in the 12 year olds by the year 2015 .

The urban population residing in the Ferozepur city of Punjab is well complemented by a large agriculture based rural populace. This study aims at estimating and comparing the caries prevalence in rural and urban 12 year old school going children of Ferozepur city using $\mathrm{SiC}$ index taking into account the gender, socioeconomic status, oral hygiene measures, awareness towards dental treatment and dietary habits.

Correspondence to: Bhawna Arora, Department of Pedodontics and Preventive Dentistry, Adesh institute of dental sciences \& research, Bathinda, India; E-mail: aroradrbhawna@gmail.com

Key words: dental caries, prevalence, WHO, DMFT, SiC value, BOHS

Received: March 25, 2015; Accepted: April 20, 2015; Published: April 23, 2015 


\section{Method}

This cross-sectional study was carried in the Department of Pedodontics and Preventive Dentistry, Genesis Institute of Dental sciences and Research, Ferozepur, Baba Farid University of Health Sciences, Faridkot, Punjab.

Oral examinations were carried out in classrooms with the help of a plain mirror and Explorer No. 5 (German SS API ${ }^{\mathrm{R}}$, Ashoo Sons Ltd., ISO 9001, New Delhi) under daylight or, where necessary, using a portable source of light. The same examiner performed all examinations. No radiographs were taken. Ethical approval for this study was obtained from the Ethics Committee of Genesis institute of Dental Sciences and Research, Ferozepur. The number of carious defects, fillings and missing primary teeth were recorded on examination forms in accordance with WHO criteria and the $\mathrm{dmft}$ scores were calculated according to WHO guidelines. Individuals were grouped into tertiles according to their $\mathrm{dmft}$ values. The $\mathrm{SiC}$ index was calculated as the mean $\mathrm{dmft}$ of the onethird of the population with the highest caries scores

\section{Sample size and distribution}

A sample of 1000 school going children of Ferozepur with age $12+$ 1 years having permanent dentition with equal distribution for urban $(\mathrm{n}=500)$ and rural $(\mathrm{n}=500)$ areas were randomly selected (Table 1$)$.

A questionnaire that includes the details regarding age, gender, socioeconomic status, parent's education level, oral hygiene measures, visit to dentist and dietary habits was filled by the single examiner with the parent's consent explaining the aim, characteristics and importance of the study and asking for their child's participation. The recording assistant was allowed to sit close enough to the examiner so that instructions and codes could be easily heard and the examiner could see that findings were being recorded correctly.

Data analysis was done using statistical package SPSS version 16. Kolmogorov-Smirnov test was applied for testing whether distribution is normal $(p>0.05)$. Descriptive statistics that included mean, standard deviation and percentages were calculated for each of the categories. $\mathrm{z}$-test was used to determine whether significant differences were present in mean DMFT and SiC values between two groups. Categorical data were analyzed by chi-square test for differences between groups. Significance for all statistical tests was predetermined at a probability value of 0.05 or less. Multiple logistic regressions were done to identify significant risk factors for DMFT.

\section{Results}

In study population, the rural population showed a higher caries prevalence of $55.8 \%$ as compared with the urban population having a prevalence of $39.8 \%$ with a highly significant difference $\left(\chi^{2}=25.64, p=0.001\right)$.

Table 1. Area wise distribution of sample.

\begin{tabular}{|l|l|l|c|}
\hline Region & Distribution & Gender & No. of Patients examined \\
\hline \multirow{2}{*}{ Region 1-Ferozepur City } & \multirow{2}{*}{ Urban } & Males & 250 \\
\hline \multirow{2}{*}{ Region 2-Wazidpur village } & \multirow{2}{*}{ Rural } & Females & 250 \\
\hline \multirow{2}{*}{ Region 3-Malwal village } & \multirow{2}{*}{ Rural } & Males & 50 \\
\hline \multirow{2}{*}{ Region 4-Khalchiyan Village } & \multirow{2}{*}{ Rural } & Males & 50 \\
\hline \multirow{2}{*}{ Region 5-Lakhoke village } & \multirow{2}{*}{ Rural } & Females & 100 \\
\hline & & Fales & 100 \\
\hline & & Females & 50 \\
\hline
\end{tabular}

Table 2. Area wise distribution of mean DMFT among the study population.

\begin{tabular}{|l|l|l|l|l|l|l|}
\hline Area & Mean & N & SD & Median & z-value & p-value \\
\hline Rural & 1.43 & 500 & 1.718 & 1.00 & & \\
\hline Urban & .92 & 500 & 1.452 & 0.00 & $\mathbf{5 . 3 9 6}$ & $<.001 * *$ \\
\hline Total & 1.17 & 1000 & 1.610 & 0.00 & & \\
\hline
\end{tabular}

${ }^{*} \mathrm{p}<0.05$-Significant; $*$ * $<<0.01$-Highly Significant

Table 3. SiC values according to area in the study population.

\begin{tabular}{|l|l|l|l|l|l|l|}
\hline Area & Mean value of SiC & $\mathbf{N}$ & SD & Median & z-value & p-value \\
\hline Rural & 3.42 & 167 & 1.420 & 3.00 & \multirow{6}{*}{-v69 } & $<\mathbf{0 . 0 0 1} * *$ \\
\hline Urban & 2.55 & 167 & 1.459 & 2.00 & & \\
\hline Total & 2.99 & 334 & 1.502 & 3.00 & & \\
\hline
\end{tabular}

${ }^{*} \mathrm{p}<0.05$-Significant; ${ }^{* *} \mathrm{p}<0.01$-Highly Significant

The mean DMFT of the children was 1.17 [standard deviation (SD) 1.610]. The $\mathrm{SiC}$ index value was 2.99 ( $\mathrm{SD}=1.502)$. About $47.8 \%$ of children had experienced dental caries. Father and mother's education played a non-significant role in experience of dental caries among children ( $p>0.05$ ) (Table 2 and 3). Caries prevalence rates among rural and urban population in relation to different frequencies of tooth brushing came out to be statistically non-significant except in individuals who did not brush daily (6.4\%), in individuals who brushed once daily (62.8\%) and individuals who brush more than once a day (37.2\%). The difference in caries prevalence rates in these groups came out be statically significant and the values were $\chi^{2}=7.554, \mathrm{p}=0.006$ and $\chi^{2}=34.11, \mathrm{p}=0.000$ respectively.

In rural subjects, 297 children had been visiting the dentist and 158 (53.2\%) of them were affected with dental caries. 203 children had never visited the dentist, and 121 (59.6\%) of them were affected. Among urban subjects 324 had been visiting the dentist, and 137 (42.3\%) of them had dental caries. 176 children had never visited the dentist and $62(35.2 \%)$ of them were affected with a highly statistically significant value $\left(\chi^{2}=7.402, \mathrm{p}=0.007\right.$ and $\chi^{2}=22.437, \mathrm{p}<0.001$ respectively). Vegetarian and mixed diet played a significant role in prevalence of dental caries in rural as well as urban areas with a prevalence of $60.3 \%$ and $43.8 \%$ in rural and urban areas respectively $\left(\chi^{2}=12.818, \mathrm{p}=0.001\right.$ and $\left.\chi^{2}=6.671, \mathrm{p}=0.010\right)$.

The multiple logistic regression model in which the dependent variable is dental caries and the demographic independent variables are area, gender, father's education, mother's education, frequency of snacking, brushing frequency, sweetened milk, dietary habits and visit to dentist. In both groups children who had visited a dentist were more likely to have dental caries than those who had never visited a dentist $(\mathrm{OR}=5.22)$. The risk of dental caries was significantly higher among children who did not brush daily $(\mathrm{OR}=7.174)$ and children who brushed once daily $(\mathrm{OR}=2.321)$. Vegetarian diet also played a significant role as a risk factor for dental caries $(\mathrm{OR}=7.132)$ as compared to mixed diet. There was no significant difference in the distribution of dental caries by area, sex, parent's education, frequency of snacking and intake of sweetened and non-sweetened milk (Table 4).

\section{Discussion}

The 'Significant Caries Index' ( $\mathrm{SiC}$ ) proposed by the World Health Organization (WHO) was used to draw attention to individuals with the highest caries scores in each population as mean DMFT/S values cannot correctly reflect the skewed distribution, leaving high caries groups undiscovered in the general population. The overall caries prevalence has been found to be $47.8 \%$. According to National Oral 
Table 4. Multiple logistic regression model for the study population.

\begin{tabular}{|c|c|c|c|c|c|c|}
\hline & & $\mathbf{N}$ & $\begin{array}{c}\text { Marginal Percentage } \\
(\%)\end{array}$ & Df & $\begin{array}{c}\text { OR } \\
(95 \% \mathrm{CI})\end{array}$ & p-value \\
\hline \multirow{2}{*}{ Caries } & Absent & 522 & $52.2 \%$ & & & \\
\hline & Present & 478 & $47.8 \%$ & & & \\
\hline \multirow{2}{*}{ Gender } & Males & 498 & $50.0 \%$ & \multirow{2}{*}{1} & \multirow{2}{*}{0.822} & \multirow{2}{*}{0.152} \\
\hline & Females & 502 & $50.0 \%$ & & & \\
\hline \multirow{2}{*}{ Area } & Rural & 500 & $50 \%$ & \multirow{2}{*}{1} & \multirow{2}{*}{1.327} & \multirow{2}{*}{0.146} \\
\hline & Urban & 500 & $50 \%$ & & & \\
\hline \multirow{6}{*}{ Father's education } & Illiterate & 134 & $13.4 \%$ & \multirow{6}{*}{5} & 1.662 & 0.172 \\
\hline & Primary school & 170 & $17 \%$ & & 1.830 & 0.068 \\
\hline & High school & 239 & $23.9 \%$ & & 1.564 & 0.135 \\
\hline & Secondary school & 210 & $21 \%$ & & 0.949 & 0.862 \\
\hline & Graduate & 134 & $13.4 \%$ & & 1.334 & 0.327 \\
\hline & Post- graduate & 109 & $10.9 \%$ & & - & - \\
\hline \multirow{6}{*}{ Mother's education } & Illiterate & 222 & $22.2 \%$ & \multirow{6}{*}{5} & 1.102 & 0.794 \\
\hline & Primary school & 139 & $13.9 \%$ & & 0.840 & 0.625 \\
\hline & High school & 188 & $18.8 \%$ & & 0.871 & 0.644 \\
\hline & Secondary school & 186 & $18.6 \%$ & & 0.899 & 0.718 \\
\hline & Graduate & 139 & $13.9 \%$ & & 0.902 & 0.713 \\
\hline & Post-graduate & 126 & $12.6 \%$ & & & \\
\hline \multirow{4}{*}{ Frequency of snacking } & 0 & 133 & $13.3 \%$ & \multirow{4}{*}{3} & \multirow{4}{*}{0.867} & \multirow{4}{*}{0.343} \\
\hline & 1 & 154 & $15.4 \%$ & & & \\
\hline & 2 & 343 & $34.3 \%$ & & & \\
\hline & $>\mathbf{3}$ & 370 & $37 \%$ & & & \\
\hline \multirow{4}{*}{ Brushing frequency } & Not everyday & 44 & $4.4 \%$ & \multirow{4}{*}{3} & 7.174 & $0.000 * *$ \\
\hline & Once a day & 520 & $52 \%$ & & 2.321 & $0.019 *$ \\
\hline & Twice a day & 388 & $38.8 \%$ & & 1.979 & 0.059 \\
\hline & Thrice a day & 48 & $4.8 \%$ & & - & - \\
\hline \multirow{2}{*}{ Sweetened milk } & No & 50 & $5 \%$ & \multirow{2}{*}{1} & \multirow{2}{*}{0.545} & \multirow{2}{*}{.067} \\
\hline & Yes & 950 & $95 \%$ & & & \\
\hline \multirow{2}{*}{ Visit to dentist } & No & 379 & $37.9 \%$ & \multirow{2}{*}{1} & \multirow{2}{*}{5.22} & \multirow{2}{*}{$0.026^{*}$} \\
\hline & Yes & 621 & $62.1 \%$ & & & \\
\hline \multirow{2}{*}{ Diet } & Vegetarian & 714 & $71.4 \%$ & \multirow{2}{*}{1} & 7.132 & $0.000 * *$ \\
\hline & Mixed diet & 286 & $28.6 \%$ & & & 0.000 \\
\hline
\end{tabular}

OR-Odd's ratio; CI-confidence interval; Df-degrees of freedom; *p<0.05-Significant; **p $<0.01$-Highly Significant

Health Survey, 2002-2003, the caries prevalence rate was $53.8 \%$ at the age of 12 years. This variation could be because of difference in criteria used for caries diagnosis, variations in the personal and dietary habits and difference in the oral hygiene measures which have marked influence on the caries prevalence.

In the present study, caries prevalence among school children in urban area $(39.8 \%)$ was lower as compared to school going children in rural area (55.8\%) [9-11]. On the other hand a few studies reported higher prevalence rate in urban areas [11-14].

There is no universally accepted relation of socio-economic status with oral disorders. This may be because socio-economic status is a broad categorization. But usually higher prevalence of dental caries was reported in lower socioeconomic strata. That may be due to lower educational status, primitive idea about oral hygiene and significance of dental caries and non availability of preventive and curative facility. In the present study caries prevalence was lower among males (44.8\%) as compared with females (50.8\%) but the difference in prevalence rates was not statistically significant. Different risk factors among males and females such as difference in eruption timings among males and females, different salivary composition and flow rates, hormonal fluctuations, more cariogenic oral microflora, dietary habits, genetic variations, and particular social roles among their family are mentioned in studies conducted till date.
The mean DMFT of the total study population was 1.17. Mean DMFT among school children of urban area (0.92) was lower than that of rural area (1.43) with statistically significant difference. The mean $\mathrm{SiC}$ value of study population was 2.99 . SiC values among rural and urban study population came out to be 3.42 and 2.55 respectively and this difference between the $\mathrm{SiC}$ values was highly significant.

The reasons for disparity between treated and untreated dental caries among both rural and urban school children could be less availability or utilization of dental services, lack of parental knowledge regarding maintenance of oral health care or inaccessibility to affordable dental services. The present study shows a significant correlation between socioeconomic status and $\mathrm{SiC}$ index with a value of 3.42 in rural population which is above the WHO goal for the year 2015.

Socioeconomic status takes into account the educational status, occupation and income of the family. These are the factors which affect the prevalence of various disorders and probably oro-dental diseases are not an exception. Mother's education was found to be associated with dental caries in the present study.

The effects of socioeconomic status and poor education are all encompassing, affecting the parent's ability to obtain employment and subsequently to provide adequate shelter, nutrition and health care for the child. Dental health awareness is transferred to the children through the parents and better oral hygiene practices are learnt. So, 
parents play a major role in terms of preventing the incidence of dental caries in their children.

In the study population, decreased caries prevalence was seen with increase in brushing frequency. Among rural population, caries prevalence among individuals who do not brush, brushing once daily, twice daily and more than twice daily was found to $50 \%, 56.66 \%$, $58.3 \%$ and $29.4 \%$ respectively. The difference among children not brushing every day, brushing once daily and twice daily groups was not statistically significant except for the group with individuals brushing more than twice daily with the least caries prevalence. In urban study population, caries prevalence was found to be $100 \%$ in children not brushing everyday, $34.44 \%$ in children brushing once daily, $42.6 \%$ in children brushing twice daily and $29 \%$ among children brushing more than twice daily with a statistically significant difference in association with the studies conducted by different authors [10,15-17].

Dental health education, school dental health programs, routine dental checkup and parent's awareness towards dental health care plays an important decisive factor in prevalence of dental caries. Taking this into consideration, study population was divided into two groups of individuals who visited the dentist and who did not visit the dentist. The results were statistically significant when comparing the caries prevalence among rural and urban population in relation with the two parameters. This suggests that adolescents who regularly visit a dentist are more sensitive to, or aware of their own oral health, and that regular checkups can help to preserve intact teeth from caries attack.

The caries prevalence was compared according to the frequency of snacking, mixed and vegetarian diet and drinks laced with carbohydrate. All these factors presented with a positive correlation with dental caries among rural and urban study groups. Present study has showed that increase in dental caries is associated with increase in degree of exposure to cariogenic factors.

There are a number of other factors that have an effect on the development of dental caries and the present study negates the traditional concept of sole association of carbohydrate rich food and development of dental caries.

In Ferozepur city, the dental caries prevalence was found to be $47.8 \%$ with a mean $\mathrm{SiC}$ value of $2.99+1.502$ and DMFT of $1.17+1.610$. The caries experience showing a skewed distribution means that there is a subgroup of the population with a higher severity of the disease. This finding also supports the observation that caries risk is itself skewed with the main risk factors being gender variations, dietary habits, oral hygiene measures and in between meal snacking. High risk groups will continue to have a high risk of future caries attack and progression.

\section{Conclusion}

The lack of dental health awareness, poor oral hygiene measures, socioeconomic status, gender variations, improper dietary habits and less utilization of dental health care services in Ferozepur is the main reason for high prevalence of dental caries. Dental health education and caries preventive programs are needed to minimize caries incidence in this area.

With the caries experience showing skewed distribution, instead of whole population strategy, attention should be drawn to the skewed distribution of dental caries within the population. There are still large groups of individuals who have considerably more caries than the WHO/FDI target level of SiC index 3 by the year 2015. So, the high risk strategy to control dental caries can be more effective in this area.
Since the results of this study might be replicated across similar sets of population across India, the dental health education and preventive dentistry programs are the need of the hour. The dental schools, the practitioners of dentistry, the state and national government and the social organizations as well as NGOs need to get together and bring awareness regarding preventive dentistry at the doorstep of the common man.

\section{References}

1. Saxena S, Shashikiran ND (2010) Prevalence of dental caries and treatment needs among hemophilic children of Kota city, Rajasthan. Annals and Essences of Dentistry 2: $18-21$.

2. Lukacs JR, Largaespada LL (2006) Explaining sex differences in dental caries prevalence: saliva, hormones, and "life-history" etiologies. Am J Hum Biol 18: 540555. [Crossref]

3. Fabrizio $\mathrm{F}$ et al. Role of social class in caries occurrence in 12 year olds in Turin, Italy European Journal of Public Health 1999; 9: 109-113.

4. Doifode VV, Ambadekar NN, Lanewar AG (2000) Assessment of oral health status and its association with some epidemiological factors in population of Nagpur, India. Indian J Med Sci 54: 261-269. [Crossref]

5. Adekoya-Sofowora CA, Nasir WO, Oginni AO, Taiwo M (2006) Dental caries in 12-year-old suburban Nigerian school children. Afr Health Sci 6: 145-150. [Crossref]

6. Bönecker M, Cleaton-Jones P (2003) Trends in dental caries in Latin American and Caribbean 5-6- and 11-13-year-old children: a systematic review. Community Dent Oral Epidemiol 31: 152-157. [Crossref]

7. Bagramian RA, Garcia-Godoy F, Volpe AR (2009) The global increase in dental caries A pending public health crisis. Am J Dent 22: 3-8. [Crossref]

8. Bratthall D (2000) Introducing the Significant Caries Index together with a proposa for a new global oral health goal for 12-year-olds. Int Dent J 50: 378-384. [Crossref]

9. Zerfowski M, Koch MJ, Niekusch U, Staehle HJ (1997) Caries prevalence and treatment needs of 7- to 10-year-old schoolchildren in southwestern Germany. Community Dent Oral Epidemiol 25: 348-351. [Crossref]

10. Khan NB et al. Caries in primary school children: Prevalence, severity and pattern in Al-Ahsa, Saudi Arabia. Saudi Dental Journal 200; 13:71-74

11. Irigoyen ME, Luengas IF, Yashine A, Mejía AM, Maupomé G (2000) Dental caries experience in Mexican schoolchildren from rural and urban communities. Int Dent $J$ 50: 41-45. [Crossref]

12. Olsson B, Segura-Bernal F, Tanda A (1989) Dental caries in urban and rural areas in Mozambique. Community Dent Health 6: 139-145. [Crossref]

13. Subrata S, Subrata S (1996) Prevalence and severity of dental caries and oral hygiene status in rural and urban areas of Calcutta. J Indian Soc Pedod Prev Dent 14: 17-20. [Crossref]

14. Mandal KP, Tewari AB, Chawla HS, Gauba KD (2001) Prevalence and severity of dental caries and treatment needs among population in the Eastern states of India. $J$ Indian Soc Pedod Prev Dent 19: 85-91. [Crossref]

15. Leske GS, Ripa LW, Barenie JT (1976) Comparisons of caries prevalence of children with different daily toothbrushing frequencies. Community Dent Oral Epidemiol 4: 102-105. [Crossref]

16. Sufia S (2009). Maternal factors and child's dental health. J Oral Health Comm. Dent $2009 ; 3: 45-48$.

17. Pakpour AH, Hidarnia A, Hajizadeh E, Kumar S, Harrison AP (2011) The status of dental caries and related factors in a sample of Iranian adolescents. Med Oral Patol Oral Cir Bucal 16: e822-827. [Crossref]

Copyright: (C2015 Arora B. This is an open-access article distributed under the terms of the Creative Commons Attribution License, which permits unrestricted use, distribution, and reproduction in any medium, provided the original author and source are credited. 